\title{
Improved Sliding Mode Controller for Shunt Active Power Filter
}

\begin{abstract}
Attia Sahara*, Abdelhalim Kessal ${ }^{\dagger}$, Lazhar Rahmani* and Jean-Paul Gaubert**
Abstract - In this work, nonlinear control of a three-phase shunt active power filter (SAPF) has been studied and compared to classical control based on proportional integral regulator. The control strategy is based on the direct current method using sliding mode control (SMC), where the aim is to regulate the average voltage across the dc bus of the inverter. Details are given for the control algorithm; the controller is comprised of a current loop which utilizes a hysteresis controller to generate the gating signals for the switching devices, and a nonlinear controller based on SMC law which is different from classical laws based on error between reference and measured output voltage of the inverter. Sliding surface applied in this work contains the whole of state variables, in order to ensure full control of the system behavior in the presence of disturbances that affect the supply source, the load parameters or the reference value. The designed controller offers advantage that it can gives the improvement of dynamic and static performances in cases of large disturbances. A comparison of the effects of PI control and SMC on the APF response in steady stat, under line variations, load variations, and different component variations is performed.
\end{abstract}

Keywords: Shunt active power filter, PI control, Sliding mode control, Harmonic, Nonlinear control.

\section{Introduction}

The widespread application of rectifier loads and variable speed drives is increasingly introducing non sinusoidal waveforms into power supply networks [1]. The deviation current component, required by such distorting loads, can be defined as a component that remains after subtractions of the active current component from the total load current [2]. The deviation current may be broken down into two components: a leading or lagging displacement of the fundamental current and the potentially aperiodic distortion current [3].

The fact is that every component of the distorting load will inevitably vary in accordance with the load condition, results in a time dependent power system harmonic [4], this implies that the conventional passive filters must be designed to meet the KVA rating of the worst case at each harmonic frequency to improve power factor and reduce harmonics, however, they have the demerits of fixed compensation level, large size and resonance. An alternative compensator structure can be realized with lower KVA rating of the worst case total distortion. This compensator injects harmonic currents to exactly cancel the distorting effect of nonlinear loads [5]. For a balanced three-phase system, waveform correction is possible without any instantaneous real power flow to or from compensator [6].

Sliding mode control has been successfully applied to

$\dagger \quad$ Corresponding Author: Faculty of Sciences \& Technology, Bordj Bou Arreridj University, Algeria. (Abdelhalim.kessal@yahoo.fr)

* LAS Laboratory, Setif1 University, Algeria. (\{Sahara_attia, Lazhar_rah\}@yahoo.fr)

* LIAS Laboratory, University of Poitiers, France. (jean-paulgaubert@univ-poitiers.fr)

Received: June 16, 2015; Accepted: December 6, 2015 variety of switching converters, usually resulting in acceptable performance with a simplified control law implementation for both linear plant and nonlinear plants $[7,8]$. Variable structure control is a high speed switching feedback control [9], with selects the appropriate switching configuration of the converter as a function of the instantaneous state variables in order to drive the state of concerned system to a predesigned surface in the phase plane [10]. The most distinguished feature of a sliding mode system is its insensitivity to parametric uncertainty and external disturbances, stability even for large line and load variations, robustness, good dynamic response, and simple implementation [11, 12].

The added value of this work is hidden in the nature of the selected sliding surface which encompasses all state variables, which allows a full control in the presence of wide disturbances [13, 14].

In this paper, an SMC for the average voltage across the dc bus regulation of the inverter is presented. The controller utilizes a law in a feedback loop based on the status of the line current and output dc voltage. This approach is fundamentally different from past work on the control of active power filters, which commonly present feed forward control schemes that rely on measurements of the load current to calculate the desired waveforms of the converter. Results demonstrate the flexibility of the APF for providing a comprehensive solution for the different power quality issues involved.

\section{System Configuration}

Fig. 1 Shows the basic scheme used for this study, where 


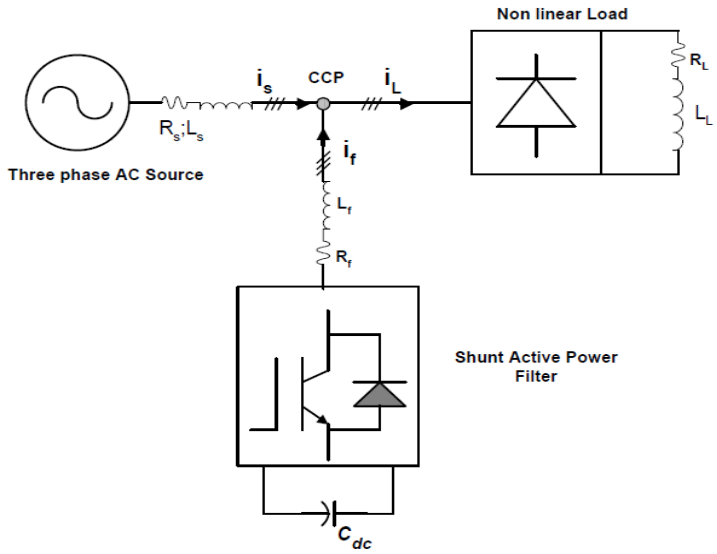

Fig. 1 Shunt active power filter circuit diagram

the network consists of three-phase voltages with fixed frequency and internal parameters $\left(\mathrm{R}_{\mathrm{s}}, \mathrm{L}_{\mathrm{s}}\right)$. The shunt active power filter (SAPF) is a device which is connected in parallel; it can compensate the reactive power and harmonic currents from a nonlinear load. The resulting total current drawn from the AC main is sinusoidal. Ideally, the SAPF needs to generate just enough harmonic current to compensate the nonlinear loads in the line. In SAPF depicted in Fig. 1, a controlled current by voltage source inverter is used to generate the compensating current $\left(i_{f}\right)$ and is injected into the utility power source grid. This cancels the harmonic components drawn from the nonlinear load and let the utility line current $\left(i_{\mathrm{s}}\right)$ sinusoidal.

A voltage source inverter with IGBT switches and an energy storage capacitor on dc bus is implemented as a SAPF. The SAPF, which is composed of inductor $\mathrm{L}_{\mathrm{f}}$ and voltage source inverter, is coupled at the common coupling point (CCP). The nonlinear load is considered as three phase rectifier supplying a load $\left(\mathrm{R}_{\mathrm{L}}, \mathrm{L}_{\mathrm{L}}\right)$.

\section{Control Strategy}

The controller is comprised of a inner current control loop which utilizes an hysteresis fixed band current control to generate the gating signals for the switching devices, and an outer voltage control loop which utilizes tow controllers based first on a PI control, followed by a sliding mode control law which regulates the average across the dc bus of the inverter.

The compensation current of the APF is given by

$$
\begin{gathered}
i_{f}(t)=i_{L}(t)-i_{S}(t) \\
i_{S}(t)=I_{S \max 1} \cdot \cos \left(f_{S 1}\right) \sin (\omega t) \\
i_{f}(t)=\sum_{n=1}^{\infty} I_{S \max n} \sin \left(n \omega t+\phi_{S n}\right)-I_{S \max 1} \cos \phi_{S 1} \sin (\omega t)
\end{gathered}
$$

It is very clear that the compensation current is composed with the reactive $\left(i_{\mathrm{fr}}\right)$ and the harmonics components $\left(\mathrm{i}_{\mathrm{fh}}\right)$.

$$
\begin{gathered}
\mathrm{i}_{\mathrm{f}}(\mathrm{t})=\mathrm{i}_{\mathrm{fr}}(\mathrm{t})-\mathrm{i}_{\mathrm{fh}}(\mathrm{t}) \\
\mathrm{i}_{\mathrm{fr}}(\mathrm{t})=\mathrm{I}_{\mathrm{Smax} 1} \cdot \cos \left(\phi_{\mathrm{S} 1}\right) \sin (\omega \mathrm{t}) \\
\mathrm{i}_{\mathrm{fh}}(\mathrm{t})=\sum_{\mathrm{n}=2}^{\infty} \mathrm{I}_{\text {Smax n }} \sin \left(\mathrm{n} \omega \mathrm{t}+\phi_{\mathrm{Sn}}\right)
\end{gathered}
$$

With an appropriate control of the SAPF, we can quasi compensate the reactive power $\left(\varphi_{\mathrm{s} 1}=0\right)$ and eliminate all harmonics components $(\mathrm{THD}=0)$.

\section{Output Voltage Controller Design}

The bloc scheme in Fig. 2 gives the configuration of the SAPF control where the dc-bus voltage is regulated by adjusting the amplitude of the reference current. A controller, in the dc-bus voltage control loop, is used to provide current reference amplitude command $I_{S M r e f}$. The sinusoidal shape of the input current, and the reactive power is set to zero are achieved by sensing the input voltage with phase locked loop (PLL). The PLL output is multiplied by $I_{S M r e f}$ to obtain the instantaneous current reference $i_{\text {Sref }}$. The current reference and the sensed input current make the input signals of the hysteresis fixed band current controller to achieve unity power factor operation. In this work two controllers are designed. The first is based on conventional PI controller; the second is based on sliding mode control.

\subsection{Rectifier choice:}

The rectifier is connected under three voltages grid, nominal power is $\mathrm{P}$, and the load voltage can be given as:

$$
\mathrm{V}_{\text {load }}=\frac{3 \mathrm{~V}_{\text {grid }} \sqrt{6}}{\pi} \cos \alpha
$$

$\alpha$ : firing angle. Load resistance is calculated as:

$$
\mathrm{R}_{\text {load }}=\frac{V_{\text {load } \max }^{2}}{P_{\max }}
$$

Inductor value is obtained from: $\tau_{\text {load }}=\frac{L_{\text {load }}}{R_{\text {load }}}$, as 3 phases bridge, $\mathrm{T}_{\text {load }}=3.3 \mathrm{~ms}$, in order to obtain a smooth current $\frac{\tau_{\text {load }}}{T_{\text {load }}} \geq 1$.

\subsection{Sizing of active filter}

Load efficient current is given as: $I_{\text {load.eff }}=\sqrt{\frac{2}{3}} I_{\text {load }}$, in this case, the effective value of the sum of the harmonic currents $\left(\mathrm{I}_{\text {eff }}\right)_{\text {harm }}$ can be presented by: 
$\left(I_{\text {eff }}\right)_{\text {harm }}=\sqrt{I_{\text {eff }}^{2}-I_{1}^{2}},\left(\mathrm{I}_{1}\right.$ : efficient value of fundamental component of alternative side). By deduction:

$$
\left(I_{\text {eff }}\right)_{\text {harm }}=\sqrt{\left(\frac{2}{3}-\frac{6}{\pi^{2}}\right) I_{\text {load }}^{2}}=0.242 I_{\text {load }}
$$

\section{Control Techniques}

\subsection{Conventional PI controller}

As shown in Fig. 2, the obtained output voltage error is used as input for PI controller, the output of the controller is the instantaneous amplitude of the reference current command $I_{\text {SMref }}$.

The system in Fig. 2 is modeled as a first order system:

$$
\frac{V_{d c}^{2}}{I_{s M r e f}}=\frac{V_{S M} \cdot R}{1+\frac{R C}{2} S}
$$

The transfer function of the PI controller is:

$$
\mathrm{f}(s)=\frac{1+K_{p} \cdot T_{i} \cdot S}{T_{i} \cdot S}
$$

\subsection{Sliding Mode controller}

Mathematical model of SAPF in the $d q$ axes is given by:

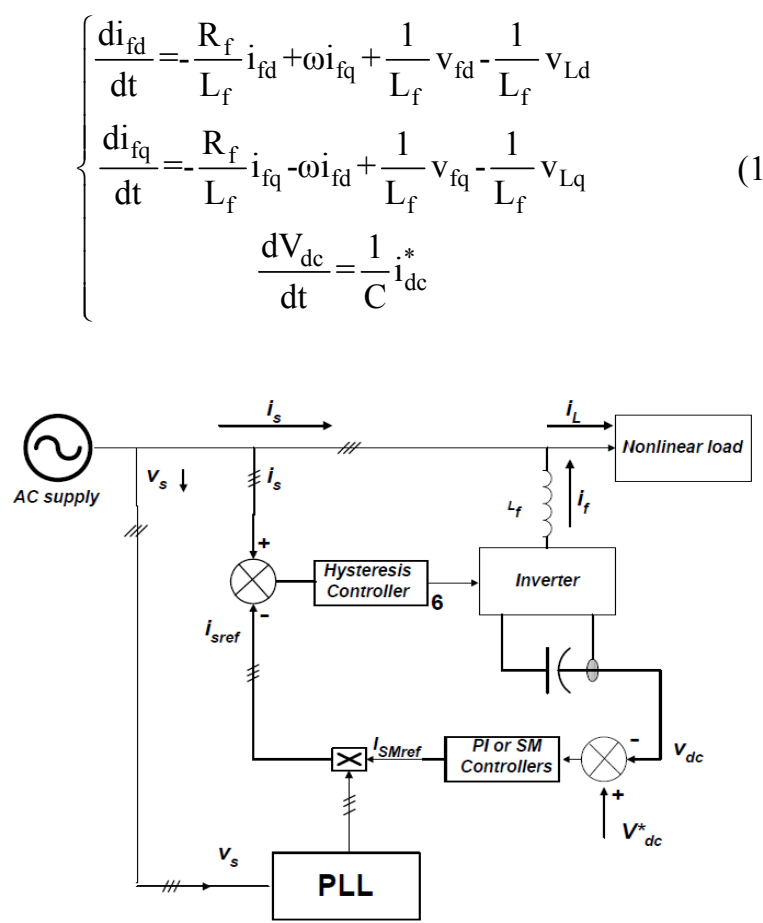

Fig. 2 Synoptic control diagram of the SAPF
The three phase loads currents $i_{L 1,2,3}$ is based on Clark transformation to obtain synchronous reference frame loads currents $i_{l d q}$ according to the following equation.

$$
\left[\begin{array}{l}
\mathrm{i}_{\mathrm{Ld}} \\
\mathrm{i}_{\mathrm{Lq}}
\end{array}\right]=\sqrt{\frac{2}{3}}\left[\begin{array}{ccc}
\cos (\theta) & \sin \left(\theta-\frac{2 \pi}{3}\right) & \cos \left(\theta+\frac{2 \pi}{3}\right) \\
-\sin (\theta) & -\sin \left(\theta-\frac{2 \pi}{3}\right) & -\sin \left(\theta+\frac{2 \pi}{3}\right)
\end{array}\right]\left[\begin{array}{l}
\mathrm{i}_{\mathrm{L} 1} \\
\mathrm{i}_{\mathrm{L} 2} \\
\mathrm{i}_{\mathrm{L} 3}
\end{array}\right]
$$

Based on the SRF theory [15-16], the currents $i_{l d}$ and $i_{l q}$ can be expressed as the sum of two components, a continuous and another alternative, such as:

$$
\left[\begin{array}{l}
\mathrm{i}_{\mathrm{Ld}} \\
\mathrm{i}_{\mathrm{Lq}}
\end{array}\right]=\left[\begin{array}{l}
\overline{\mathrm{i}}_{\mathrm{Ld}}+\tilde{\mathrm{i}}_{\mathrm{Ld}} \\
\overline{\mathrm{i}}_{\mathrm{Lq}}+\tilde{\mathrm{i}}_{\mathrm{Lq}}
\end{array}\right]
$$

With $\bar{i}_{L d}+\bar{i}_{L q}$ and $\tilde{i}_{L d}+\tilde{i}_{L q}$ : are the direct and alternative components of $i_{L d}$ and $i_{L q}$, respectively.

To obtain the direct and alternative current components of the reference state variable vector $x^{*}, i_{L d}$ can be extracted by exploring SRF theory, and by low pass filter (LPF) to calculate the reference component $i_{f d}^{*}$ (alternative components).

The model (12) is a multi-input multi-output nonlinear system [17-20], in case of SAPF with sliding mode control, the outputs filter are $i_{f d}, i_{f q}$ and $V_{d c}$, and the control variables are $v_{f d}{ }^{*}, v_{f q}{ }^{*}$, and $i_{d c}$ are the reference voltages and the switching losses current respectively. The model (12) can be written into the following state space general form [18]:

$$
\begin{gathered}
\dot{X}=A X+B u+D \\
X=\left[\begin{array}{c}
i_{f d} \\
i_{f q}
\end{array}\right], \quad u=\left[\begin{array}{c}
* \\
v_{f d}^{*} \\
v_{f q}^{*}
\end{array}\right], \quad A=\left[\begin{array}{cc}
-\frac{R_{f}}{L_{f}} & -\omega \\
-\omega & -\frac{R_{f}}{L_{f}}
\end{array}\right], \quad B=\left[-\frac{1}{L_{f}}\right], \\
C=\left[\begin{array}{c}
-\frac{1}{L_{f}} v_{L d} \\
-\frac{1}{L_{f}} v_{L q}
\end{array}\right], \quad K=\left[\begin{array}{cc}
k_{d} & 0 \\
0 & k_{q}
\end{array}\right], \quad K_{i}=\left[\begin{array}{cc}
k_{i d} & 0 \\
0 & k_{i q}
\end{array}\right]
\end{gathered}
$$

Eq. (16) represents sliding surfaces of the filter currents $i_{f d}, i_{f q}$

$$
\begin{gathered}
S(X)=K\left(X^{*}-X\right)+K_{i} \int\left(X^{*}-X\right) d t \\
X^{*}=\left[\begin{array}{c}
x_{1}^{*} \\
x_{2}^{*}
\end{array}\right]=\left[\begin{array}{c}
i_{f d}^{*} \\
i_{f q}^{*}
\end{array}\right]=\left[\begin{array}{c}
\tilde{i}_{L d}-i_{L d} \\
i_{L q}
\end{array}\right]
\end{gathered}
$$

The switching losses current $i_{\mathrm{dc}}$ is calculated as follow:

$$
\mathrm{u}_{\mathrm{v}}=\mathrm{i}_{\mathrm{dc}}=\mathrm{c}_{1} \mathrm{x}_{3} \mathrm{y}_{1}+\mathrm{c}_{2} \mathrm{x}_{4} \mathrm{y}_{2}
$$


Where: $y_{1}$ and $y_{2}$ are the switching functions

$$
\begin{aligned}
x_{3}=e\left(V_{d c}\right) & =V_{d c}{ }^{*}-V_{d c}, x_{4}=\dot{x}_{3}, x_{5}=\int x_{3} d t \\
\mathrm{y}_{1} & =\left\{\begin{array}{ccc}
1 & \text { if } & \mathrm{x}_{3} \cdot \mathrm{S}\left(\mathrm{x}_{3}\right)>0 \\
-1 & \text { if } & \mathrm{x}_{3} \cdot \mathrm{S}\left(\mathrm{x}_{3}\right)<0
\end{array}\right. \\
\mathrm{y}_{2} & =\left\{\begin{array}{ccc}
1 & \text { if } & \mathrm{x}_{4} \cdot \mathrm{S}\left(\mathrm{x}_{3}\right)>0 \\
-1 & \text { if } & \mathrm{x}_{4} \cdot \mathrm{S}\left(\mathrm{x}_{3}\right)<0
\end{array}\right.
\end{aligned}
$$

The sliding surface $\mathrm{S}\left(\mathrm{x}_{3}\right)$ of the DC bus voltage is given by Eq. (21) [17].

$$
\begin{gathered}
S\left(x_{3}\right)=S\left(V_{d c}^{*}-V_{d c}\right)=c_{k} x_{3}+x_{4}+c_{i} x_{5} \\
S\left(x_{3}\right)=c_{k} e\left(V_{d c}\right)+\frac{d}{d t} e\left(V_{d c}\right)+c_{i} \int e\left(V_{d c}\right) d t
\end{gathered}
$$

$\mathrm{c}_{\mathrm{k}}, \mathrm{c}_{\mathrm{i}}$ are positive constants.

The two sliding surfaces of the filter currents $i_{f d}, i_{f q}$ are:

$$
\left\{\begin{array}{l}
S\left(i_{f d}\right)=k_{d}\left(i_{f d}^{*}-i_{f d}\right)+k_{i d} \int\left(i_{f d}^{*}-i_{f d}\right) d t \\
S\left(i_{f q}\right)=k_{q}\left(i_{f q}^{*}-i_{f q}\right)+k_{i q} \int\left(i_{f q}^{*}-i_{f q}\right) d t
\end{array}\right.
$$

During the sliding mode,

$$
\left\{\begin{array}{l}
\mathrm{S}\left(\mathrm{i}_{\mathrm{fd}}\right)=\mathrm{S}\left(\mathrm{i}_{\mathrm{fq}}\right)=0 \\
\dot{\mathrm{S}}\left(\mathrm{i}_{\mathrm{fd}}\right)=\dot{\mathrm{S}}\left(\mathrm{i}_{\mathrm{fq}}\right)=0
\end{array}\right.
$$

The control variables are given by:

$$
\mathrm{u}=\left[\begin{array}{c}
* \\
\mathrm{v}_{\mathrm{fd}} \\
* \\
\mathrm{v}_{\mathrm{fq}}^{*}
\end{array}\right]=\mathrm{u}_{\mathrm{dis}}+\mathrm{u}_{\mathrm{eq}}
$$

Solving the equation (10) gives the expression of the equivalent command as follows:

$$
\mathrm{u}_{\mathrm{eq}}=(\mathrm{K} . \mathrm{B})^{-1}\left[\mathrm{~K}_{\mathrm{i}}\left(\dot{\mathrm{X}}^{*}-\mathrm{X}\right)-\mathrm{K}\left(\dot{\mathrm{X}}^{*}-\mathrm{AX}-\mathrm{D}\right)\right]=\left[\begin{array}{c}
\mathrm{u}_{\text {eqd }} \\
\mathrm{u}_{\text {eqq }}
\end{array}\right]
$$

If the trajectories are different from the state of the sliding surface, the discontinuous control ensures decrease the distance between the state trajectory and the sliding surface [18]. In our case, we chose:

$$
\mathrm{u}_{\mathrm{dis}}=\left[\begin{array}{l}
\mathrm{u}_{\text {disd }} \\
\mathrm{u}_{\mathrm{disq}}
\end{array}\right]=\operatorname{Sign}(\mathrm{S}(\mathrm{X})) \cdot \mathrm{U}_{\mathrm{MAX}}
$$

\section{Simulations Results}

These two controllers are verified using MATLAB/
Table 1. Specifications adopted for the simulated inverter

\begin{tabular}{c|c}
\hline $\mathrm{V}_{\mathrm{s}}, \mathrm{f}$ & $50 \mathrm{~V}(\mathrm{rms}), 50 \mathrm{~Hz}$ \\
\hline $\mathrm{R}_{\mathrm{s}}, \mathrm{L}_{\mathrm{s}}$ & $0.1 \Omega, 0.566 \mathrm{mH}$ \\
\hline $\mathrm{R}_{\mathrm{f}}, \mathrm{L}_{\mathrm{f}}$ & $0.01 \Omega, 1 \mathrm{mH}$ \\
\hline $\mathrm{L}_{\mathrm{c}}, \mathrm{L}_{\mathrm{L}}$ & $0.566 \mathrm{mH}, 1 \mathrm{mH}$ \\
\hline $\mathrm{R}_{\mathrm{L} 1}, \mathrm{R}_{\mathrm{L} 2}$ & $11.66 \Omega,(11.66+10) \Omega$ \\
\hline $\mathrm{V}_{\mathrm{dc}}, \mathrm{C}$ & $140 \mathrm{~V}, 1100 \mu \mathrm{F}$ \\
\hline $\mathrm{HB}($ hysteresis $)$ band $)$ & 0.17 \\
\hline $\mathrm{K}_{\mathrm{p}}, \mathrm{K}_{\mathrm{i}}$ & $0.3,23$
\end{tabular}

Without using the APF compensation, the $\mathrm{THD}_{\mathrm{i}}=27.48 \%$.

Simulink. SAPF model is developed to simulate a switchon and change load transient conditions, with the same control scheme in Fig.2 from the above study the selected parameters for simulation are presented in Table 1 (simulation parameters are the same used in practice):

\subsection{Conventional PI controller}

Fig. 3 shows waveforms during load change, when the load current is increased, capacitor voltage decreases to compensate for the real power supplied by source and in the contrary when load current is decreased. The dynamic of PI controller is found to be satisfactory, the steady-state is reached within 3 cycles, after filtering; THD will be $1.26 \%$.

Fig. 4 shows that steady-state is reached within 2 cycles

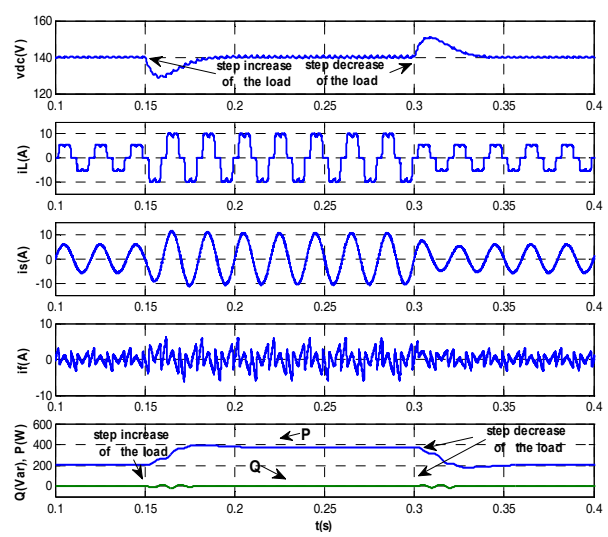

Fig. 3 Waveforms for Load changes (21.66 $\Omega$ to $11.66 \Omega$ )

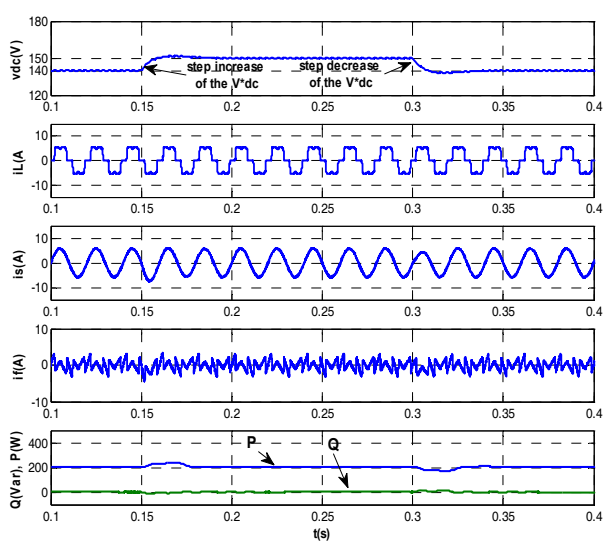

Fig. 4 Waveforms for $V_{d c}^{*}$ changes (140V to $150 \mathrm{~V}$ ) 


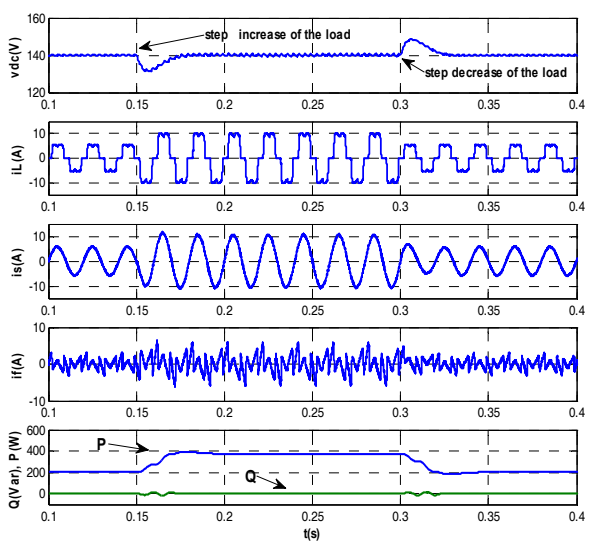

Fig. 5. Waveforms for Load changes $(21.66 \Omega$ to $11.66 \Omega)$
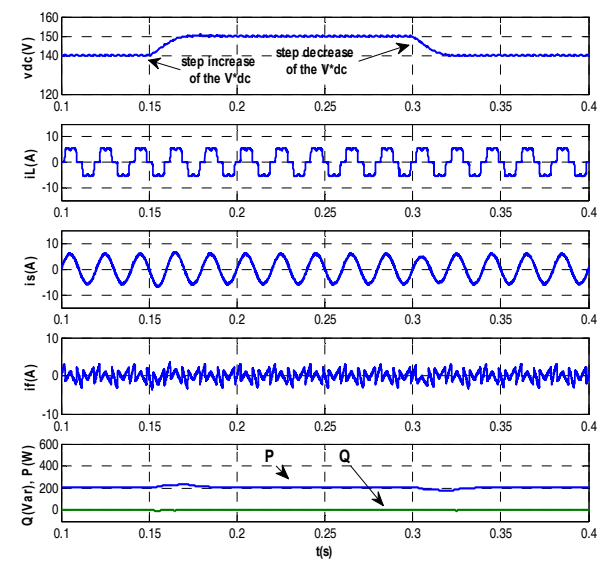

Fig. 6. Waveforms for $V_{d c}^{*}$ changes (140V to $\left.150 \mathrm{~V}\right)$

Table 2. Parameters under transient conditions.

\begin{tabular}{|c|c|c|c|}
\hline \multicolumn{2}{|c|}{ Parameter } & $\begin{array}{c}\text { PI } \\
\text { Controller }\end{array}$ & $\begin{array}{c}\text { SM } \\
\text { Controller }\end{array}$ \\
\hline \multicolumn{2}{|c|}{ Setting time } & 3 cycles & 1 cycle \\
\hline \multirow{2}{*}{$\begin{array}{c}v_{d c}(\text { rise/drop }) \\
\% \text { of } V_{d c}^{*}\end{array}$} & $\begin{array}{l}\text { load change from } \\
21.66 \Omega \text { to } 11.66 \Omega\end{array}$ & $7.85 \%$ & $6.42 \%$ \\
\hline & $11.66 \Omega$ to $21.66 \Omega$ & $7.85 \%$ & $6.07 \%$ \\
\hline \multirow{2}{*}{$\begin{array}{l}v_{d c} \text { peak to } \\
\text { peak ripple }\end{array}$} & $21.66 \Omega$ & $0.6 \mathrm{~V}$ & $0.55 \mathrm{~V}$ \\
\hline & $11.66 \Omega$ & $1.2 \mathrm{~V}$ & $1.10 \mathrm{~V}$ \\
\hline
\end{tabular}

under a step change of dc side capacitor voltage reference.

\subsection{Sliding mode controller}

Fig. 5 shows waveforms during load change, when the load current is increased, dc voltage decreases to compensate for the real power supplied by the source and in the contrary when load current is decreased. The dynamic performance of SMC is found to be satisfactory, and the steady-state is reached within 1 cycle. THD of the supply current is $1.45 \%$.

Fig. 6 shows the APF waveforms under a step change of dc side capacitor voltage reference. The dynamic SM controller is found to be satisfactory, and the steady-state condition is reached within 1 cycle. Table 2 presents a numeral comparative between PI and SMC controllers.

\section{Experimental Results}

The SAPF experimental test bench used was developed in LIAS laboratory, University of Poitiers. It was achieved with a VSI of $20 \mathrm{KVA}$ based on a three-phase IGBT $1200 \mathrm{~V}$, 50A (SKM 50GB 123D). To ensure dead time of control signals and the insulation, a developed card based on the IXDP630 component and the driver circuits SKHI 22 are used. The control strategy is implemented using a singleboard DS1104 maufactured by dSPACE and performed under the integrated development environnment of MATLAB/Simulink RTW.

\subsection{Conventional PI controller}

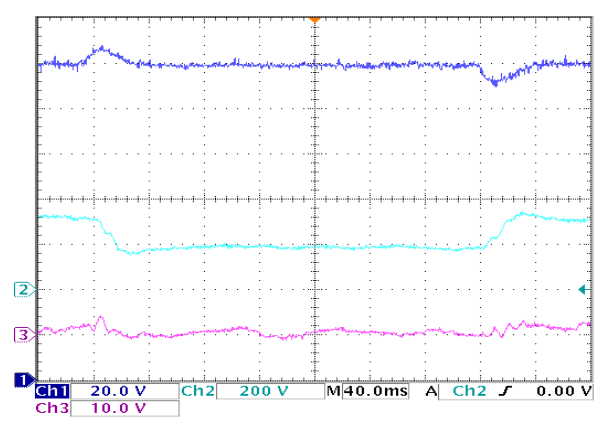

Fig. 7. APF waveforms, $v_{\mathrm{dc}}$, P and Q (with Load changes)

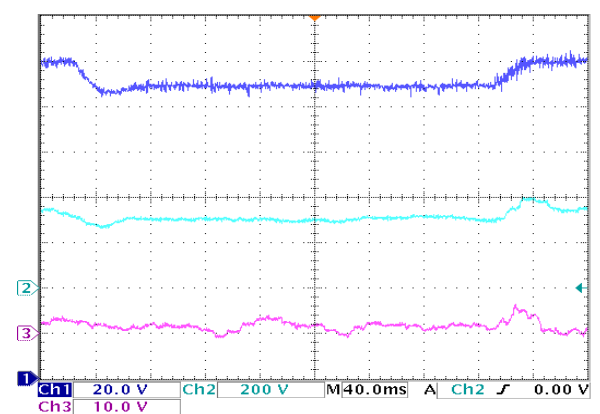

Fig. 8. APF waveforms $v_{d c}$, P and Q (with $V_{d c}^{*}$ changes)

\subsection{Sliding mode controller}

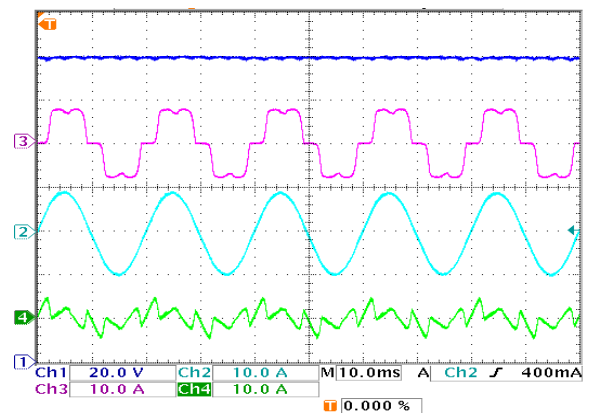

Fig. 9. APF waveforms, $v_{\mathrm{dc}}, i_{f}, i_{S}, i_{L}$, (steady state) 


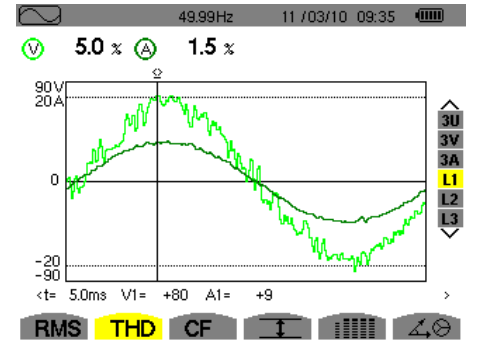

Fig. 10. Voltage and current (Source) THD

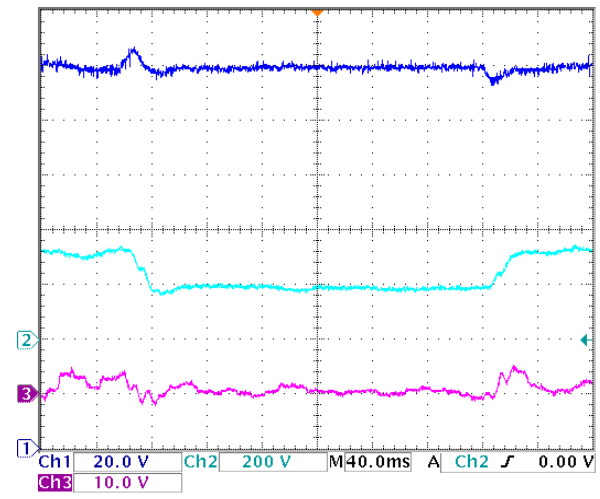

Fig. 11. APF waveforms, $v_{d c}$, P and Q (with Load changes)

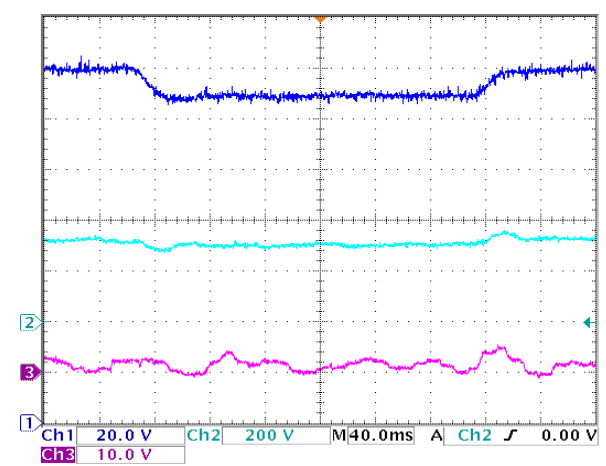

Fig. 12. APF waveforms, $v_{\mathrm{dc}}, \mathrm{P}$ and $\mathrm{Q}$ (with $V_{d c}^{*}$ changes)

Table 3. Experimental transient values.

\begin{tabular}{c|c|c|c|c}
\hline & \multicolumn{2}{|c|}{ PI- Hysteresis } & \multicolumn{2}{c}{ Sliding Mode } \\
\hline Load & $\Delta v_{d c}(\mathrm{~V})$ & $\Delta \mathrm{t}(\mathrm{ms})$ & $\Delta v_{d c}(\mathrm{~V})$ & $\Delta \mathrm{t}(\mathrm{ms})$ \\
\hline $22 \Omega / 12 \Omega$ & 10 & 40 & 7 & 20 \\
\hline $12 \Omega / 22 \Omega$ & 10 & 40 & 7 & 20 \\
\hline $\boldsymbol{V}^{*} \mathrm{dc}$ & $\Delta v_{d c}$ & $\Delta \mathrm{t}(\mathrm{ms})$ & $\Delta v_{d c}$ & $\Delta \mathrm{t}(\mathrm{ms})$ \\
\hline $140 \mathrm{~V} / 130 \mathrm{~V}$ & 10 & 35 & 10 & 20 \\
\hline $130 \mathrm{~V} / 140 \mathrm{~V}$ & 10 & 35 & 10 & 20 \\
\hline
\end{tabular}

From Figures (7-12), it is remarkable that the SMC regulator is more accurate than the PI for the steady state, as it has a fast response time in case of transient state for sudden changes. Table 3 resumes a comparative study based on numeral values between the classical controller using a PI with hysteresis current control and nonlinear control based on SMC, it's clear that the last controller offers a fast response (around 50\% compared to PI controller response), and a $v_{d c}$ hollow amplitude less than the classical method. It's also very clear the influence of the SMC control in side of power quality with an input current $\mathrm{THD}=1.5 \%$ and a voltage distortion of $5 \%$.

\section{Conclusion}

The Simulation results show that the APF is capable to compensate reactive power and load unbalance; it reduces the harmonic level below the limit specified in IEEE-519 Standard. The results show that the SMC control has fast dynamic response to external disturbances than the PI control. The steady state performances of the SM controller are compared to the PI controller. The experimental evaluation of the simple proposed control strategy used for shunt active power filtering has proved its robustness and effectiveness. However, it has been experimentally illustrated that the SAPF is able to improve the power quality and decrease the current distortion (THD) well below the harmonics limit imposed by the IEEE-519 Standard, under unfavorable conditions of load and source.

\section{References}

[1] H. Akagi. "New Trends in Active Filters for Improving Power Quality", Proc. Drive and Energy Systems Conf., Vol.1, pp. 417- 425, 1995.

[2] B. Singh, K. Al-haddad, A. Chandra. "A Review of Active Filters for Power Quality Improvement", IEEE Trans. Ind. Elect. Vol. 46, No. 5, October 1999.

[3] M. El-habrouk, M.K. Darwish, P. Meht. "Active power filters: A Review", IEE Proc. Elect. Power Appl., Vol. 147, No. 5, Sep. 2000.

[4] S.K. Jain, P. Agrawal, H.O. Gupta. "Fuzzy Logic Controlled Shunt Active Power Filter for Power Quality Improvement", IEEE Proc.-Elect. Power Appl., Vol.149, No.5, September 2002.

[5] A. Chaoui, J.P. Gaubert, F. Krim, L. Rambault. "IP Controlled Three-Phase Shunt Active Power Filter for Power Improvement Quality". IEEE Ind. Elect. Conference IECON 2006, paper 348043, pp. 23842389.

[6] A. Chandra, B. Singh, B.N. Singh, K. Al-haddad. "An Improved Control Algorithm of Shunt Active Filter for Voltage Regulation”, Harmonic Elimination, Power factor correction, and Balancing of Nonlinear Loads. IEEE Trans. on Power Electronics, Vol. 15, No. 3, May 2000.

[7] M. Ahmed. "Sliding Mode Control for Switched Mode Power Supplies". Thesis for the degree of Doctor of science (Technology), Lappeenranta University of Technology, Lappeenranta, Finland, 
December 2004.

[8] M. Noyeripour, T. Niknam. "Design of a Three Phase Active Power Filter with Sliding Mode Control and Energy Feedback". International Journal of Electrical and Electronics Engineering 1:2 2008.

[9] Utkin "Sliding Mode Control Design Principles and Applications to Electric Drives". IEEE Trans. Ind. Elect. Vol. 40, No.1, Feb. 1993.

[10] S. Saetieo, R. Devaraj, D.A. Torry. "The Design and Implementation of a Three-Phase Active Power Filter Based on Sliding Mode Control". IEEE Trans. on Ind. Appl., Vol. 31, No. 5, pp. 993-1000, September/ October 1995.

[11] H. Bühler. "Réglage de systèmes d'électronique de puissance", Presses polytechniques et universitaires romandes, Lausanne, 1997.

[12] A. Kechich, B. Mazari. "La Commande par mode Glissant : Application à la Machine Synchrone à Aimants Permanents (approche linéaire)". Afrique Science 04(2008) 21-37.

[13] M. Nayeripour, T. Niknam "Nonlinear Sliding Mode Control Design for Shunt Active Power Filter with the Minimization of Load Current" World Applied Sciences Journal vol. 4, No. 1, 2008, pp: 124-132.

[14] L. Wei, L. Chunwen, X. Changbo "Sliding mode control of a shunt hybrid active power filter based on the inverse system method", Electrical Power and Energy Systems vol. 57, pp. 39-48, 2014.

[15] K. Bhattacharjee "Design and Simulation of Synchronous Reference Frame Based Shunt Active Power Filter using Simulink" National Conference on Challenges in Research and Technology in the Coming Decades (CRT 2013), pp. 1-7, 27-28 Sept 2013.

[16] K. Bhattacharjee "Harmonic Mitigation by SRF Theory Based Active Power Filter using Adaptive Hysteresis Control" Conference Power and Energy Systems: Towards Sustainable Energy, 13-15 March, pp. 1- 6, 2014.

[17] L. Wei, L. Chunwen, X. Changbo "Sliding Mode Control of a Shunt Hybrid Active Power Filter Based on the Inverse System Method", Electrical Power and Energy Systems, Vol. 57, pp. 39-48, 2014.

[18] F. Hamoudi, A. Chaghi, M. Adli, H. Amimeur "a Sliding Mode Control for Four-wire Shunt Active Filter", Journal of Electrical Engineering, Vol: 62, No. 5, pp. 267-273, 2011.

[19] J. Fei, T. Li, S. Zhang, "Indirect Current Control of Active Power Filter Using Novel Sliding Mode Controller" IEEE, 13th Workshop on Control and Modeling for Power Electronics (COMPEL), Kyoto, pp.1-6, 10-13 June 2012.

[20] E. J. Acordi, L. B. G. Campanhol, S. A. O. Silva, C. B. Nascimento and A. Goedtel "A Study of Shunt Active Power Filters Applied to Three-Phase FourWire Systems" International Conference on Renew- able Energies and Power Quality (ICREPQ'12) Santiago de Compostela (Spain), 28th to 30th March, 2012.

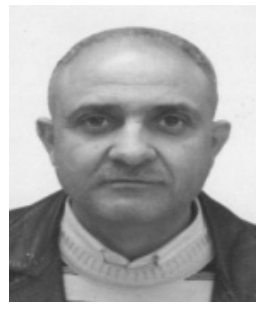

Sahara Attia was born in Algeria on 1965.He received the Engineering degree from Haouari Boumedien University of science and technology of (USTHB Bab Ezzouar), Algeria, in 1992, The master degree from the university of Setif, Algeria, in 2004. In 2005 he joined Electrotechnics Department at University of Djelfa, Algeria as an assistant professor. His major field of interest includes power converter design and control, power quality, active power filter, and system harmonics.

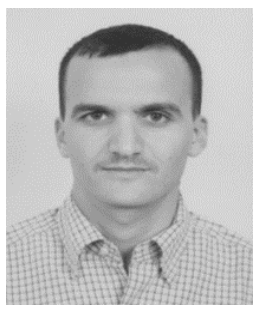

Kessal Abdelhalim was born in Algeria in 1975. He received the Engineering degree in electrical engineering from the University of Setif, Setif, Algeria, in 1997, the Master's and $\mathrm{Ph} . \mathrm{D}$ degrees in electrical engineering from the University of Setif, Algeria, in 2002 and 2012,. He is currently an Assistant Professor with the Department of Electrical Engineering, University of Bordj Bou Arreridj. His main research interests are modeling and control of power converters, fuzzy logic control, nonlinear control and predictive control applied to power electronics systems such as power factor corrector.

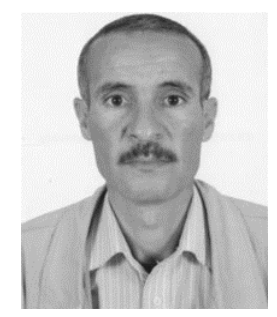

Rahmani Lazhar was born in Algeria in 1964. He received the Engineering degree in electrical engineering from university of Annaba, in 1991, and the D.E.A. and Ph.D. degrees in electrical engineering from the University of Setif, Algeria, in 1994 and 2005, respectively. $\mathrm{He}$ is currently an Assistant Professor with the Department of Electrical Engineering, University of Setif. His current research interests, with the Electrical Engineering Team of the Laboratory of Automatic, are modeling and advanced control of power converters and power electronics systems and their digital control techniques. These topics deal with power quality such as active filters. 


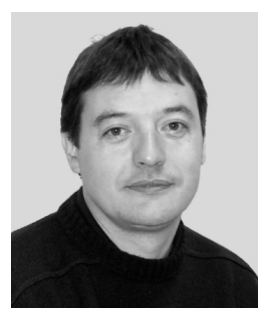

Jean-Paul Gaubert was born in France in 1965. He received the Engineer's degree from the University of Clermont-Ferrand, France, in 1988, and the M.Sc. and the Ph.D. degrees from the University of Science and Technology of LILLE, Villeneuve, France, in 1990 and 1992, respectively, all in electrical engineering. He is currently an Associate Professor with the Automatic Control and Industrial Data Processing Laboratory (LIAS), Poitiers National School of Engineering (ESIP), University of Poitiers, Poitiers, France. His current research interests include modeling and advanced control of power converters and power electronics systems and their digital control techniques. The derived topics deal with power quality such as active filters, PWM rectifiers, or renewable energy systems 